\section{Cigarette Maker's Puff}

BRITAIN's three million anglers are by their numbers a tempting bait for any producer of mass consumer goods. This has not escaped the attention of John Player and Sons of Nottingham, makers of Players No. 6, a brand of cigarettes.

Last week Players moved into a country hotel on the Thames to launch its " $£ 10,000$ Research Scheme to Help British Angling". The research scheme, a grandiose venture indeed, calls for a team of fisheries experts to cross the Channel and spend a whole three weeks in Holland, Belgium and Germany, where they will examine continental methods of conserving fish. On their return they will apply their findings for the benefit of British anglers. The team will be accompanied by a film unit which, to plagiarize the firm's own publicity, will make a "colour documentary film showing the work and findings of the delegation, to be available at lectures and on free loan to all angling clubs".

Some may suppose that a search of the scientific literature would with greater efficiency reveal any startling continental advances in fish conservancy. But such an endeavour would hardly make the subject of a film, prominently sponsored by Players and on free loan to all angling clubs. It is also hard at first to see why Players is contributing only $£ 1,000$ to the $£ 10,000$ "research" scheme and allowing the rest to be raised by angling competitions throughout Britain. But the prizes for all these competitions are being donated by Players, which is unlikely to take pains to conceal its generosity.

The fact that the scheme will take people out into the open air doubtless explains why the Minister of Sport sent a representative. He went as far as to say that "This is a great new development in the angling world, and Players are to be congratulated on their public spirited action in launching the scheme". Other members of the British Government, who have banned cigarette companies from advertising on television, and who intend to prevent them from giving away coupons with their products, may not feel quite so cheerful about the scheme.

\section{Measles Vaccine}

The Ministry of Health will launch in May a campaign to vaccinate against measles all children between the ages of 1 and 15 years who have not yet contracted the disease. Trials carried out by the Medical Research Council, and experience in the United States and elsewhere, indicate that the vaccine is highly effective and that its widespread use could lead to the eradication of measles as a childhood disease. Measles is a biennial epidemic and reported cases in an epidemic year, of which next year in Britain is one, may rise to 750,000 . For most people the disease is mild, but about one person in a hundred has to be admitted to hospital and in some cases the disease may be fatal; between 1962 and 1966 there were 434 deaths attributable to measles.

The cost of the campaign is expected to be about $£ 1$ million during the first year if the maximum number of susceptible children-between 3.4 and 4 millioncome forward for vaccination. In each subsequent year there will be about 800,000 newborns to be vaccinated in their second year of life. The money saved from not having to treat measles in the population is expected to cover amply the costs of the vaccination campaign. It is not yet known what period of immunity is conferred by the vaccine, but it is thought unlikely that booster injections will be necessary. Antibodies have been detected in children's blood up to six years after vaccination.

Children in Britain are already offered immunization in their first year of life against diphtheria, tetanus and whooping cough-these vaccines are injected together in a single "cocktail" - and against polio, which is given orally. Vaccines for smallpox, and now measles, are given in the second year of life.

\section{Health in Vietnam}

\section{by Anne Clayton}

NoT least among the troubles of the population of Vietuam is the increasing incidence of plague, cholera, typhoid and other dengue-like diseases. These infections increase wherever there are large-scale uncontrolled movements of the population. A preliminary report on the subject has now been prepared by the World Health Organization. It indicates that there is a grave danger that infections may spread to other nations of the Pacific basin. The report, prepared during the past six months at the request of the World Health Assembly, was designed to answer several questions. Is there evidence of deterioration in the level of general health of civilian populations ? Have the health services been adversely affected? Has a situation arisen in Vietnam which creates potential health hazards or problems for other countries? Any report of this nature is necessarily incomplete, but in view of the many difficulties faced by the investigators the report is a commendable effort.

For South Vietnam, the information has been provided by the official records of the WHO, WHO Epidemiological and Vital Statistics Reports, the Government of South Vietnam through the Regional Office for the Western Pacific and by reports received by the WHO quarantine unit. The account of the situation in North Vietnam is based on more limited information contained in a number of booklets which have appeared in North Vietnam together with the report of a long technical interview with the Minister of Health in North Vietnam, Dr Pham Ngoc Thach. The WHO document now issued is at pains to emphasize the incomplete character of this information, "which is not open to the usual methods of confirmation". The most recent figures in the reports refer to 1964, and the WHO report says that until official statistics are available, "the health situation in North Vietnam must remain somewhat obscure". On the basis of the com. parison which it has been possible to carry out, however, it does seem that North Vietnam is less seriously afflicted by disease than the south, and that it is taking measures to prevent the situation getting out of hand.

In South Vietnam, epidemic plague, cholera and an upsurge of syphilis and gonorrhoea are distinctive features; other communicable diseases, especially tuberculosis, together with the lack of adequate sanitation and water supply, are, however, major public health problems. Plague infection has been reported. to be widespread among rodents and fleas at certain ports and airports, and cases of the disease have now 